\title{
Alterations of Pancreatic Growth and of GP-2 Content in the Reserpinized Rat Model of Cystic Fibrosis $^{1}$
}

\author{
FRANCOIS A. LEBLOND, JEAN MORISSET AND DENIS LEBEL \\ Centre de Recherche sur les Mécanismes de Sécrétion, Faculty of Science, University of Sherbrooke, \\ Sherbrooke, $Q C$, Canada, JIK $2 R I$
}

\begin{abstract}
The chronically reserpinized rat is an experimental model for cystic fibrosis. In this study, we report the effects of two doses of reserpine $\left(0.5\right.$ and $1.0 \mathrm{mg} \cdot \mathrm{kg}^{-1}$. $\mathrm{d}^{-1}$ ) on the growth of the pancreas and on its content of the glycoprotein GP-2, a characteristic protein of the zymogen granule. An assessment of the effects of secondary malnutrition induced by the drug was also performed by adding a group of pair-fed animals. During the $7 \mathrm{~d}$ of treatment, body wt and food intake were monitored. These two parameters were significantly affected from the 4th d on. Pancreatic wt, DNA, protein, and activity of amylase and chymotrypsinogen were measured after 4 and $7 \mathrm{~d}$ of treatment; lipase activity and GP-2 content, after $7 \mathrm{~d}$. Although the DNA content never did change, total protein diminished by $27 \%$ at the higher dose of reserpine. Pancreatic wt, amylase activity and GP-2 content were reduced by the treatment, while chymotrypsinogen and lipase activities were increased. Effects on pancreatic wt, amylase, chymotrypsinogen, and GP-2 were dose-dependent. Malnutrition had effects similar to reserpine on body wt, protein, amylase, and chymotrypsinogen. Pancreatic wt, lipase, and GP-2, however, were specifically altered by the chronic reserpine treatment. It is concluded from these results that reserpine induces, in the pancreas, specific alterations that are distinguishable from the accompanying malnutrition. These findings support the use of pancreatic wt, lipase, and GP-2 as specific markers of the effects of the drug on the pancreatic tissue in the chronically reserpinized rat model for cystic fibrosis. This is the first report of a modulation of GP-2 content induced by any treatment. It suggests that GP-2 is directly affected in the pancreas of the chronically reserpinized rat. (Pediatr Res 25:478481, 1989)
\end{abstract}

$\mathrm{CF}$, cystic fibrosis

Abbreviations

GP-2, the major pancreatic granule membrane glycoprotein $R$ group, rats injected at $0.5 \mathrm{mg} \cdot \mathrm{kg}^{-1} \cdot \mathrm{d}^{-1}$ with reserpine $2 \mathrm{R}$ group, rats injected at $1.0 \mathrm{mg} \cdot \mathrm{kg}^{-1} \cdot \mathrm{d}^{-1}$ with reserpine

$\mathrm{CF}$ is the most common genetic disease in the Caucasian population, occurring once in every 2000 live births. It is characterized by a generalized disorder of the exocrine glands. The

Received July 11, 1988; accepted December 5, 1988.

Correspondence and reprint requests Dr. Denis LeBel, Department of Biology, University of Sherbrooke, Sherbrooke, QC, Canada, J1K 2R1.

Supported by a grant from the Canadian Cystic Fibrosis Foundation to D.L. D.L. is a NSERC of Canada Research Associate.

${ }^{1}$ This is the ninth paper in a series "Elucidation of the Mechanisms of Cellular Secretion." This work was submitted in partial fulfillment of M.Sc. requirements by F.A.L., Faculty of Science, University of Sherbrooke. primary defect of the CF cell is not yet known. Studies of the alterations of the pancreatic functions in $\mathrm{CF}$ have been made particularly difficult by the unavailability of pathologic human tissue. As the disease does not exist in animals, a model has been developed. Chronically reserpinized animals $(1,2)$ have been adopted as such a model because of histologic, physiologic, and biochemical similarities of treated animals with CF patients. To investigate pancreatic disorders induced by the treatment, the chronically reserpinized rat has been studied in detail (3-8). In addition to impaired exocrine secretion $(3,6)$ and decreased amylase content (8), the pancreas of treated animals also shows morphologic alterations. Ultrastructural observations on purified zymogen granule preparations show damaged membranes and a much lower density of their content $(6,9)$.

The integral protein constituting more than $25 \%$ of the proteins in the membrane of the pancreatic secretion granule is called GP-2 (10). An equivalent amount of this glycoprotein is also found as a component of the soluble zymogens in the granule content (11). No biochemical or physiologic role has yet been ascribed to GP-2, but as it is so abundant in the granule, the total amount of GP-2 could be related to the capacity of the pancreas to assemble zymogen granules efficiently. As reserpine significantly hampers the pancreatic secretory response and the assembly of granules $(6,9)$, chronic reserpine injections could possibly act through the modulation of the total amount of GP-2 in the pancreas.

This study was undertaken to determine the specific effects of reserpine treatment on parameters of pancreatic growth and on the amount of GP-2 in the gland. To do this, groups of pair-fed rats were used to discriminate between the direct effect of the drug and the effect of the diminution in food intake that the treatment induces.

\section{MATERIALS AND METHODS}

Treatments. Male Sprague-Dawley rats, weighing between 200 and $275 \mathrm{~g}$, were injected daily, intraperitoneally, with reserpine $\left(0.5\right.$ or $\left.1.0 \mathrm{mg} \cdot \mathrm{kg}^{-1}\right)$ in a solution of benzyl alcohol, polyethylene glycol 300, and acetic acid (Martinez JR, personal communication). Each group was made up of 12 individually housed rats. Two control groups were injected either with saline or with the vehicle used to dissolve the drug. No differences were observed on all the parameters measured for these two control groups. Therefore the group of animals, sham injected with the drug's vehicle, was adopted as the control. During treatment, animals received water and food (rat food) ad libitum. The control injected group of pair-fed animals received an amount of food equal to the one ingested the day before by the group treated with reserpine at $0.5 \mathrm{mg} \cdot \mathrm{kg}^{-1}$. Each animal was weighed daily before injection, and again just before being killed.

Biochemical determinations. After 4 or $7 \mathrm{~d}$ of treatment, animals were fasted overnight before they were killed by decap- 
itation. Pancreases were immediately excised, dissected to remove the fat, weighed, and split in three parts for determination of different parameters. DNA was extracted and determined from $\approx 100 \mathrm{mg}$ of tissue (one-tenth of the gland) homogenized in 0.6$\mathrm{N}$ perchloric acid $(12,13)$. The rest of the gland was divided into two identical pieces. The first piece was homogenized in ice-cold $\mathrm{Na}_{2} \mathrm{HPO}_{4}$ for protein and enzyme activity determinations. Protein, amylase, and chymotrypsinogen were assayed according to previously published procedures (14-16). Lipase was assayed by titration of the fatty acids released from a substrate of olive oil in the presence of arabic gum as an emulsifier (17). The second fragment was used for the quantitation of GP-2.

Immunochemical quantitation of GP-2 in zymogen granules. Tissue was homogenized in $0.65-\mathrm{M}$ sucrose containing $8-\mathrm{mM}$ sodium cacodylate buffer, $\mathrm{pH} 6.0$, and $0.5-\mathrm{mM}$ phenylmethylsulfonyl fluoride. In summary, the preparation of the granule fraction was done by successive differential centrifugations in buffered sucrose according to previously published procedures (18). The granule fraction was then completely solubilized in SDS-Triton X-100 in order to solubilize quantitatively all the GP-2 (19). This sample was used to determine the amount of GP-2 by immunoelectrophoresis (11). Amylase and protein determinations were carried out on a fraction that was kept free of detergent. As GP-2 was measured in a granule fraction because the homogenate of the gland contained an insufficient proportion of antigen (11), the total pancreatic content of GP-2 was estimated by dividing the amount of GP-2 measured in this granule fraction by the yield of amylase recovered in the fraction. This estimation takes into account the variation in the yield of purified granules obtained from each rat.

All data were analyzed using a nonparametric (Kruskal-Wallis) 1 -way ANOVA coupled to a multiple comparison test (Conover's test) on rank (20)

Materials. Reserpine, polyethylene glycol 300, and Triton X100 were from Sigma Chemical Co. (St. Louis, MO). SDS was from Bio Rad Laboratories (Richmond CA). All other chemicals were at least of ACS reagent grade quality.

\section{RESULTS}

Induction of the pathology was monitored throughout the course of the 7-d reserpine treatment by weighing the animals (Fig. 1) and by measuring the amount of food ingested (Fig. 2). The effect of reserpine on body wt was not significant before the 4 th $\mathrm{d}$ of treatment for the group injected with $0.5 \mathrm{mg} \cdot \mathrm{kg}^{-1}$ of reserpine ( $R$ group). For the $2 \mathrm{R}$ group, however, effect of the treatment was already significant after $2 \mathrm{~d}$ of treatment (Fig. 1). The effect on food intake for the $\mathrm{R}$ group (Fig. 2) was significant after $4 \mathrm{~d}$, as was the effect on body wt. The effect of treatment on pancreatic wt was evaluated after 4 and $7 \mathrm{~d}$ (Fig. 3). No significant differences were observed at $d 4$, but pancreases of all treated animals were significantly smaller after the 7 th $\mathrm{d}$ of injection for both the 0.5 and $1.0 \mathrm{mg} \cdot \mathrm{kg}^{-1}$ groups (Fig. 3). Pancreatic wt of the $\mathrm{R}$ group decreased by $15 \%$, the $2 \mathrm{R}$ group by $26 \%$. By contrast, while body wt of the group of pair-fed rats decreased (from $220 \pm 2.9$ at $\mathrm{d} 0$ to $202 \pm 3.0 \mathrm{~g}$ at d 7) in parallel with the group with which it was paired (R) (from $213 \pm 2.5$ at $\mathrm{d} 1$ to $194 \pm 4.6 \mathrm{~g}$ at $\mathrm{d} 7$ ), no significant decreases of pancreatic wt of these pair-fed animals were detected (Fig. 3). This latter observation shows that daily chronic reserpine injections induced a direct and dose-dependent effect on the wt of the pancreatic tissue.

Trophic effects. The effects of chronic reserpine injection on the pancreatic growth have never been measured. Consequently, we have determined the effects on total DNA in addition to the determination of total protein and content of three zymogens, for instance amylase, chymotrypsinogen and lipase. These parameters were determined after 4 and $7 \mathrm{~d}$ of treatment.

Protein and DNA contents were estimated in order to determine if the decreases observed in pancreatic wt may be due to atrophy or aplasia of the gland. Results in Table 1 reveal that

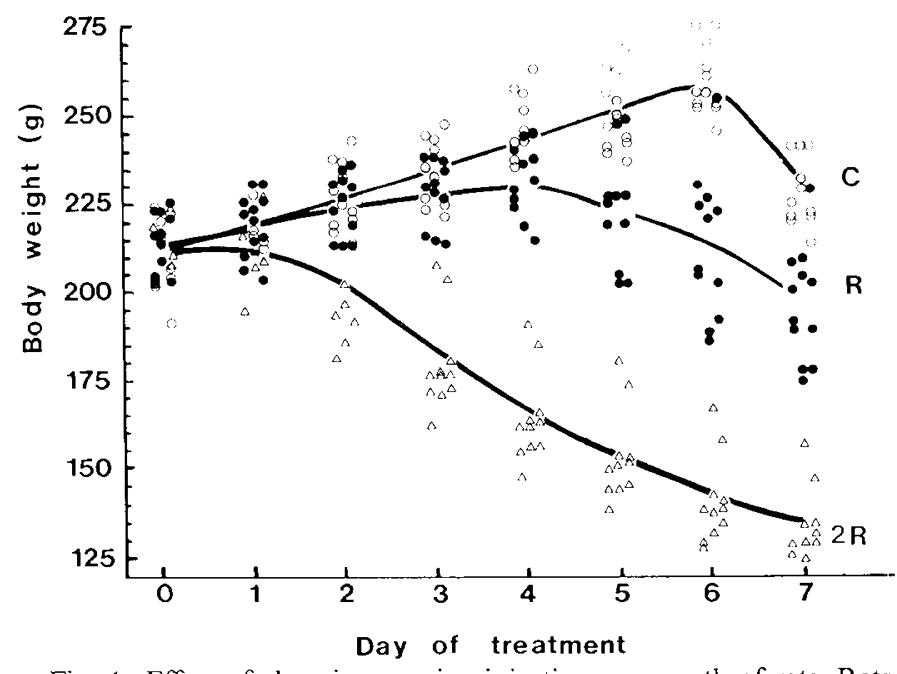

Fig. 1. Effect of chronic reserpine injection on growth of rats. Rats were weighed daily before injection. One group of 12 rats, $R$, was injected with reserpine at $0.5 \mathrm{mg} \cdot \mathrm{kg}^{-1} \cdot \mathrm{d}^{-1}$ (filled circles), another group, 2R, with $1.0 \mathrm{mg} \cdot \mathrm{kg}^{-1} \cdot \mathrm{d}^{-1}$ (open triangles). The control group, $\mathrm{C}$ (open circles), was injected with a similar vol of vehicle used to solubilize reserpine. At the end of $\mathrm{d} 6$, rats were fasted overnight before being killed. Individual rats are plotted. Differences between the control group and the treated ones were significant $(p<0.05)$ after $\mathrm{d} 4$ and $\mathrm{d} 2$ for groups $\mathrm{R}$ and $2 \mathrm{R}$, respectively. Body wt of rats in the two groups fed in pairs evolved in an identical manner.

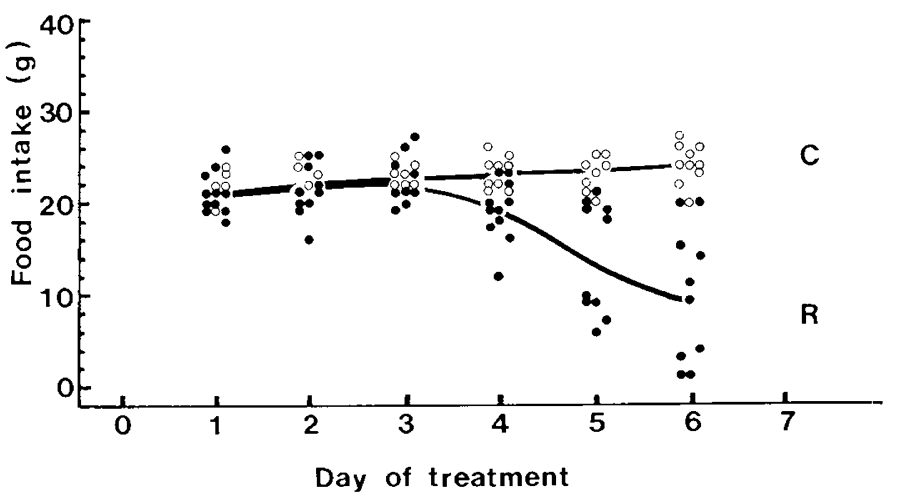

Fig. 2. Effect of chronic reserpine injection on food intake. Rats were fed with powdered rat food, and the food intake was recorded daily. Data for individual rats are plotted. The treated group of animals (12 rats), $\mathrm{R}$ (filled circles), was injected with $0.5 \mathrm{mg} \cdot \mathrm{kg}^{-1} \cdot \mathrm{d}^{-1}$ of reserpine. Food intake became significantly different $(p<0.05)$ with the group of control animals, $\mathrm{C}$ (open circles), at $\mathrm{d} 4$.

total DNA contents remained similar in all groups and at all times. As for the protein content, the only significant decrease $(-27 \%)$ was observed on the $2 \mathrm{R}$ group after $7 \mathrm{~d}$. Judging by the protein/DNA ratio, only a slight cellular atrophy was induced at the end of the treatment. As the pair-fed group of rats also showed a similar atrophy, it is concluded that cellular atrophy could also be caused by fasting and that it could not solely be attributed to the reserpine treatment.

The drug had two opposite effects on individual pancreatic zymogens. Although amylase activity decreased, chymotrypsinogen and lipase activities increased. The effect on the amylase content were progressive with time, and the amplitude of the decrease was a function of the dose of reserpine used. By contrast, increase in chymotrypsinogen content was not as dose-dependent as the variations were for amylase. Lipase content increased by $239 \%$ after $7 \mathrm{~d}$ of injection with $0.5 \mathrm{mg}$ of reserpine $/ \mathrm{kg}$. When compared to the group of pair-fed animals, effects on amylase and chymotrypsinogen were not significantly different from those of treated animals. By contrast, lipase content was dramat- 
ically increased by a factor of 2.4 in the $R$ group but was not affected in the pair-fed group. It can be concluded that fluctuations in amylase and chymotrypsinogen contents of the pancreatic tissue that were also observed in pair-fed animals could partly be imputed to the malnutrition endured by the animals during the treatment. Lipase activity, however, was drastically increased $(239 \%$ of controls) in treated animals, establishing in this case a specific effect of the drug.

$G P-2$ content of zymogen granules. Finally, variations in the amount of GP-2, the protein characteristic of the zymogen granule membrane $(10,21)$, were evaluated after treatment with reserpine. After $7 \mathrm{~d}$ at $0.5 \mathrm{mg} \cdot \mathrm{kg}^{-1}$, the content of GP-2 was decreased by $30 \%$ (Table 1). In the treated group injected with twice the dose, its content decreased by $43 \%$. By contrast, the pair-fed group of rats responded in a totally opposite manner by a remarkable increase of $370 \%$ over the control level. It thus appears that reserpine specifically depleted the pancreas of GP-2 in a dose-dependent manner, while malnutrition induced an increase in GP-2 contents. As, in the pair-fed rats, amylase contents were diminished (Table 1) and the total number of secretory granules not increased (22), the augmentation of GP-2 observed in these animals could not be attributed to an accumulation of granules in the cell.

\section{DISCUSSION}

Chronic reserpine injection of rats is presently the most accepted of the few models available to study the pathology of CF in animals. In this report, we have measured the effects of such a treatment on pancreatic growth and on the contents of zymogens as well as on the amount of a specific secretory granule protein, GP-2. These parameters were analyzed 1) to determine which one of these effects was specific to the drug and not secondary to malnutrition, 2) to assess the dose dependence of these effects, and 3) to see how the zymogen granule GP-2 protein concentration was altered during this treatment.

Our results show that daily reserpine injections for $7 \mathrm{~d}$ had a direct effect, which cannot be attributed to malnutrition, on three of the measured parameters: the lipase content, the GP-2 content, and the wt of the pancreas. This conclusion is justified by two observations: 1 ) the dose-dependence of these effects and 2) by the fact that reserpine on one side and malnutrition on the other (pair-fed animals), clearly produced different effects on

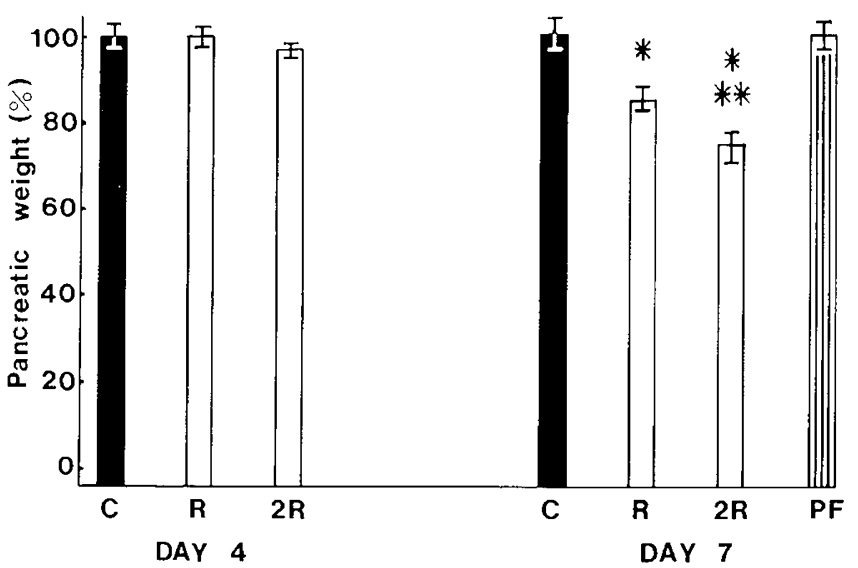

Fig. 3. Effect of chronic reserpine injection on pancreatic growth. Groups of 12 rats were injected with reserpine at $0.5 \mathrm{mg} \cdot \mathrm{kg}^{-1} \cdot \mathrm{d}^{-1}(\mathrm{R})$ or $1.0 \mathrm{mg} \cdot \mathrm{kg}^{-1} \cdot \mathrm{d}^{-1}(2 \mathrm{R})$, or with the vehicle used to solubilize the drug $(\mathrm{C})$. One group of rats was sham injected and pair fed (PF) with the $\mathrm{R}$ group. Pancreases were excised and weighed at $\mathrm{d} 4$ and $\mathrm{d} 7$ of treatment. Pancreatic wt is expressed as percentage of the sham-injected group (C) at the appropriate day. No differences were observed at $\mathrm{d} 4$ between any of the groups. Significant differences were measured at $\mathrm{d} 7$ between both treated groups ( $R$ and $2 R$ ), indicated by *. Significant differences were also observed at $\mathrm{d} 7$ between treated group $R$ and group $2 \mathrm{R}$, indicated by **. PF animals did not show any differences of pancreatic wt with control group C. these three parameters. In contrast, the decreased content of amylase, the increased content of chymotrypsinogen, and the diminution in body wt cannot specifically be attributed solely to reserpine because malnutrition alone could also induce similar effects in the group of pair-fed animals. The latter conclusions are similar to those of Hazlett et al. (23) and Webster et al. (24), who also observed that decreased levels of amylase and total proteins could be secondary to malnutrition. The increase observed in lipase content, however, was not observed by Hazlett et al. (23). They found no differences with pair-fed animals. Except for their use of subcutaneous rather than the conventional intraperitoneal injections, no major differences of protocol could easily explain these discrepancies between their observations and ours. Nevertheless, the increased lipase activities that we observed were very high (2.4-fold) and agrees with previous observations by Christophe et al. (25) that malnutrition alters differently the pancreatic contents of amylase and lipase.

Another insight into the effect of the treatment on the pancreatic tissue has been evaluated by measuring the total DNA content of the gland. As DNA contents were never affected, it can be concluded that reserpine even at a high dose $\left(1 \mathrm{mg} \cdot \mathrm{kg}^{-1}\right)$ did not alter the total number of cells in the gland, therefore the growth of the tissue. Instead, the drug affects the cellular metabolism of the pancreas, resulting in increased lipase content and decreased GP-2 content.

Pancreatic wt in the $\mathrm{R}$ and $2 \mathrm{R}$ groups diminished by $15 \%$ and $26 \%$, respectively. We know that this effect of reserpine on pancreatic wt was specifically produced by the drug in the $R$ group. These effects could not be attributed to a decrease in total pancreatic proteins as proteins constitute no more than $15 \%$ of the pancreatic wt $(23,24)$. This atrophy is probably due to a decreased water content of the tissue, as it has already been observed after fasting (24).

The behavior of GP-2 upon daily injections of reserpine and under malnutrition is the first report of a variation in the content of this glycoprotein in an experimental condition. Therefore, chronic reserpine injection is a means by which one can alter the pancreatic content of GP-2, the specific glycoprotein of the pancreatic zymogen granules. As we do not know the exact role of GP-2 in the secretory process of the pancreas, it is difficult to rationalize the possible significance of these effects. As the GP-2 protein is in continuous interaction with zymogens due to its location all along the secretory pathway (21), we raised the hypothesis that GP-2 would be in a unique position to interact with the zymogens (11). Precipitation of secretory proteins is first observed in the trans Golgi as a signal for routing zymogens to secretory granules (26). It is subsequently required for the condensation (27) as well as osmotic inactivation of the proteins in the mature granule. In this report, two major variations in the content of GP-2 were observed. The first one is a dose-dependent decrease of GP-2 after treatment with reserpine. The second one is a drastic 3.7-fold increase of GP-2 in the pair-fed group of animals. The correlation between the decreased GP-2 content and the altered secretory responsiveness of the gland, which according to ultrastructural observations $(6,9)$ would be caused by a serious impairment in the formation of secretory granules, leads us to conclude that there may be a possible role for GP-2 in one of these aggregations of zymogens that lead to zymogen granule formation.

In this report, we showed that changes in pancreatic wt, lipase, and GP-2 were directly attributable to the effects of the drug on the pancreatic tissue. We also confirmed the observations of Hazlett et al. (23), that alterations in some of the commonly measured parameters (amylase, proteins, body wt, and chymotrypsinogen) could be secondary to the malnutrition induced by chronic reserpine injections and should therefore be viewed with caution before any conclusions may be drawn. Biochemical variations induced by reserpine injections were accompanied by characteristic ultrastructural alterations of the pancreatic tissue. These observations are reported in a companion paper (22).

In conclusion, taking into account the possible effects of 
Table 1. Pancreatic content of zymogens, DNA, and GP-2 after 4 and $7 d$ of injection with reserpine at $0.5 \mathrm{mg} / \mathrm{kg} / \mathrm{d}(\mathrm{R})$ and $1.0 \mathrm{mg} / \mathrm{kg} / \mathrm{d}(2 \mathrm{R})^{*}$

\begin{tabular}{lcccccccc}
\hline \multicolumn{1}{c}{ Group } & No. & & \multicolumn{3}{c}{ Prot/DNA } & & \\
& rats & DNA \% & Protein $\%$ & $\%$ & Amylase \% & Chymotg \% & Lipase \% & GP-2 \% \\
\hline R (d 4) & 12 & $103 \pm 3.49$ & $118 \pm 2.86 \dagger$ & $115 \pm 2.73$ & $79.3 \pm 3.11 \dagger$ & $177 \pm 13.73 \dagger$ & ND & ND \\
R (d 7) & 27 & $99.2 \pm 4.60$ & $96.8 \pm 5.55$ & $99 \pm 6.26$ & $62.8 \pm 2.67 \dagger$ & $128 \pm 13.7 \dagger$ & $239 \pm 38.6 \dagger \ddagger$ & $70.9 \pm 6.76 \dagger \ddagger$ \\
2R (d 4) & 15 & $110 \pm 4.97$ & $108 \pm 2.45$ & $100 \pm 6.69$ & $84.3 \pm 2.76 \dagger$ & $134 \pm 8.71 \dagger$ & ND & ND \\
2R (d 7) & 15 & $91.8 \pm 3.21$ & $72.8 \pm 6.15 \dagger$ & $78.1 \pm 4.86 \dagger$ & $43.6 \pm 2.94 \dagger$ & $143 \pm 12.6 \dagger$ & ND & $57.2 \pm 5.04 \dagger$ \\
Pair-fed sham (d 7) & 12 & $110 \pm 3.01$ & $85.9 \pm 3.40$ & $77.6 \pm 2.67 \dagger$ & $71.7 \pm 5.18 \dagger$ & $115 \pm 24.3 \dagger$ & $97 \pm 20.3$ & $372 \pm 12.87 \dagger$ \\
\hline
\end{tabular}

* Results are expressed as percentage of mean value of the control at the appropriate $d$ of treatment \pm SEM; ND, not determined.

$\uparrow$ Significantly different from control group $(p<0.01)$.

$\ddagger$ Significantly different from pair-fed group (paired with $\mathrm{R}$ rats) at $\mathrm{d} 7(p<0.01)$.

malnutrition by including appropriate pair-fed animals and measuring parameters that are specifically modified by reserpine (pancreatic wt, lipase, and GP-2), the chronically reserpinized rat can be viewed as a reliable model for CF. The significant decrease in the amount of the zymogen granule GP-2 protein is the first report of such an alteration in the content of this particular pancreatic glycoprotein. It suggests that the function of GP-2 could be directly or indirectly linked to some of the manifestations of the pathology in the exocrine pancreas.

Acknowledgments. The authors acknowledge the excellent technical assistance of Marlyne Beattie and Micheline Vanier. Many thanks to Dr. Brian Talbot for very helpful comments.

\section{REFERENCES}

1. Martinez JR, Adelstein E, Quissel D, Barbero GJ 1975 The chronically reserpinized rat as a possible model for cystic fibrosis. Pediatr Res 9:463469

2. Shiffman ML, Gillon MJ, Galey WR 1982 Pancreatic function in the reserpinized rabbit-a model for cystic fibrosis. I. Effect of secretin. Pediatr Res 16:104-108

3. Perlmutter J, Martinez JR 1978 The chronically reserpinized rat as a model for cystic fibrosis. VII. Alterations in the secretory response to cholecystokinin and to secretin from the pancreas in vivo. Pediatr Res 12:188-194

4. Setser ME, Spicer SS, Simson JAV, Adamson M, Martinez JR 1979 The effects of reserpine on the ultrastructure and secretory responses of rat exocrine pancreas. Exp Mol Pathol 31:413-422

5. Morton D, Parker D, Estrada P, Martinez JR 1980 Exocrine pancreatic secretion in rats treated with reserpine after stimulation with pilocarpine, dopamine, caerulein. Pediatr Res 14:18-20

6. McCurdy RE, Martinez JR 1981 The chronically reserpinized rat as a model for cystic fibrosis: alterations in pancreatic enzyme secretion and storage. Pediatr Res 15:1308-1313

7. Roomans GM, Wei X, Ceder O, Kollberg H 1982 The reserpinized rat in the study of cystic fibrosis: $x$-ray microanalysis of submandibular gland and pancreas. Ultrastruct Pathol 3:285-293

8. Joehl RJ, DeJoseph MR 1985 Pancreatic enzyme secretion in experimental cystic fibrosis. In: Martinez JR, Barbero GJ (eds) Animal Models for Cystic Fibrosis: The Reserpine-Treated Rat. San Francisco Press, San Francisco, pp 119-124

9. Spicer SS, Simson JAV, Martinez JR 1985 Cytochemical and ultrastructural alterations induced by reserpine in exocrine glands. In: Martinez JR, Barbero GJ (eds) Animal Models for Cystic Fibrosis: The Reserpine-treated Rat. San Francisco Press, San Francisco, pp 13-21

10. LeBel D, Beattie M 1984 The integral and peripheral proteins of the zymogen granule membrane. Biochim Biophys Acta 769:611-621

11. Paquette J, Leblond FA, Beattie M, LeBel D 1986 Reducing conditions induce a total degradation of the major zymogen granule membrane protein in both its membranous and its soluble form. Immunochemical quantitation of the two forms. Biochem Cell Biol 64:456-462

12. Mainz DL, Black O, Webster PD 1973 Hormonal control of pancreatic growth. $\mathrm{J}$ Clin Invest 52:2300-2304

13. Volkin E, Cohn W 1954 Estimation of nucleic acids. Biochem Anal 1:287303

14. Lowry OH, Rosebrough NJ, Farr A, Randall RJ 1951 Protein measurement with the Folin phenol reagent. J Biol Chem 193:265-275

15. Bernfeld P 1955 Amylase $\alpha$ and $\beta$. Methods Enzymol 1:149-158

16. Hummel BC 1959 A modified spectrophotometric determination of chymotrypsin, trypsin and thrombin. Can J Biochem Physiol 37:1393-1399

17. Larose L, Morissat J 1977 Acinar cell responsiveness to urecholine in the rat pancreas during fetal and early post-natal growth. Gastroenterology 73:530 533

18. Pâquet MR, St.-Jean P, Roberge M, Beaudoin AR 1982 Isolation of zymogen granules from rat pancreas and characterization of their membrane proteins. Eur J Cell Biol 28:20-26

19. Plumley FG, Schmidt GW 1983 Rocket and crossed immunoelectrophoresis of proteins solubilized with sodium dodecyl sulfate. Anal Biochem 134:8695

20. Nadeau D, Paradis D, Fouquette L, Dunnigan J 1988 In vitro toxicology data on respirable particles and fibers and evaluation for statistical significance. In: Goldberg AM (ed) Alternative Methods in Toxicology Series, vol 6 Progress in In Vitro Toxicology. Mary Ann Liebert Inc, New York, pp $237-$ 251

21. Geuze HJ, Slot JW, van der Ley PA, Scheffer RCT 1981 Use of colloidal gold particles in double-labeling immuno-electron microscopy of ultrathin frozen sections. J Cell Biol 89:653-665

22. Grondin G, Leblond FA Morisset J, LeBel D 1988 Light and electron microscopy of the exocrine pancreas in the chronically reserpinized rat. Pediatr Res 25:482-489, 1989

23. Hazlett D, Korc M, Brannon PM 1986 Effects of malnutrition and chronic reserpine treatment on pancreatic exocrine function. Pediatr Res 20:12361239

24. Webster PD, Singh M, Tucker PC, Black O 1972 Effects of fasting and feeding on the pancreas. Gastroenterology 62:600-609

25. Christophe J, Camus J, Deschodt-Lanckman M, Rathé J, Robberecht P, Vandermeers-Piret MC, Vandermeers A 1971 Factors regulating biosyn. thesis, intracellular transport and secretion of amylase and lipase in the rat exocrine pancreas. Horm Metab Res 3:393-403

26. Tooze J, Tooze SA 1986 Clathrin-coated vesicular transport of secretory proteins during the formation of ACTH-containing secretory granules in AtT 20 cells. J Cell Biol 103:839-850

27. Reggio H, Dagorn JC 1980 Packaging of pancreas secretory proteins in the condensing vacuoles of the Golgi complex. In: Ribet A, Pradayrol L, Susin $C$ (eds) Biology of Normal and Cancerous Exocrine Pancreatic Cells, INSERM Symp. No. 15. Elsevier/North-Holland, Amsterdam, pp 229-244 